Revista da Rede Brasileira de História da Geografia e Geografia Histórica

$12 \mid 2019$

Geografia Histórica em questão

\title{
De volta para o futuro
}

Um método para a geografia humana segundo Paul Vidal de la Blache Back to the future: A method for human geography according to Paul Vidal de la Blache

Retour vers le futur : Un méthode pour la géographie humaine selon Paul Vidal de la Blache

Volver al futuro: Un método para la geografía humana según Paul Vidal de la Blache

\section{Guilherme Ribeiro}

\section{(2) OpenEdition}

Journals

Edição electrónica

URL: https://journals.openedition.org/terrabrasilis/5468

DOI: 10.4000/terrabrasilis.5468

ISSN: 2316-7793

Editora

Rede Brasileira de História da Geografia e Geografia Histórica

Refêrencia eletrónica

Guilherme Ribeiro, «De volta para o futuro», Terra Brasilis [Online], 12 | 2019, posto online no dia 29 dezembro 2019, consultado o 05 dezembro 2022. URL: http://journals.openedition.org/terrabrasilis/ 5468 ; DOI: https://doi.org/10.4000/terrabrasilis.5468

Este documento foi criado de forma automática no dia 5 dezembro 2022

All rights reserved 


\section{De volta para o futuro}

Um método para a geografia humana segundo Paul Vidal de la Blache

Back to the future: A method for human geography according to Paul Vidal de la Blache

Retour vers le futur : Un méthode pour la géographie humaine selon Paul Vidal de la Blache

Volver al futuro: Un método para la geografía humana según Paul Vidal de la Blache

\section{Guilherme Ribeiro}

\section{NOTA DO EDITOR}

O presente comentário, elaborado pelo professor Guilherme Ribeiro, serve como apresentação ao texto Sobre o raciocínio geográfico (Sur l'esprit géographique, 1914), de Paul Vidal de la Blache, que a Terra Brasilis oferece a seus leitores neste número, em tradução do mesmo professor.

\section{NOTA DO AUTOR}

Pesquisa financiada pela Fundação Carlos Chagas Filho de Amparo à Pesquisa do Estado do Rio de Janeiro (FAPERJ) - Apoio a grupos emergentes de pesquisa do Estado do Rio de Janeiro.

\section{Tradução como deslocamento rumo a uma história prospectiva da geografia: breves notas de método}

1 No âmbito das Ciências Humanas, poucas atitudes são tão infundadas quanto negligenciar o passado. Não importa qual seja a "instância" a ser estudada, a noção de 
processo a ela se associa de forma inexorável. Se em termos individuais lembranças ruins ou traumas assombram a todos em maior ou menor grau, em termos coletivos memória e história conformam as maneiras pelas quais sociedades e instituições concomitantemente reproduzem e alteram o mundo. Todavia, entre o reino dos vivos paira um tipo de pretensão que lhes impele a se desobrigar do passado. Vive-se como se "ele" nunca tivesse existido. Em tempos de crise, porém, observa-se com clareza sua relevância, pois direita e esquerda, homens e mulheres, elites e trabalhadores a ele recorrerão como álibi inconteste a justificar suas práticas, comportamentos e valores. Logo, o passado (isto é, o tempo, a memória, o esquecimento, a recordação, a história) é um objeto eminentemente político.

2 No domínio da Geografia, nossa pontual intervenção por intermédio da tradução visa a questionar a imagem de Vidal de la Blache consagrada tanto por brasileiros quanto por franceses e, simultaneamente, a entender as razões e os agentes que a projetaram de uma forma - e não de outra. Ao efetuarmos deslocamentos temporais, espaciais e linguístico-culturais do século dezenove e início do vinte para o final do século vinte e começo do vinte e um, da Europa para a América do Sul e do francês para o português brasileiro, tal projeto não alimenta a fantasia de buscar a "verdade" sobre Vidal ou restituir a "integralidade" de seu pensamento, mas promover a circulação do conhecimento e, com efeito, outras leituras sobre sua herança. Neste movimento, a tradução atua como uma espécie de senha a abrir portas outrora fechadas ou de difícil acesso. Assim, tal como a abordamos e diferente do que pode soar à primeira vista, a história da geografia é um campo que aponta para o futuro da disciplina e não "apenas" para o seu "passado". Não é normativo, mas prospectivo.

3 Eis o sentido conferido ao título De volta para o futuro, pois estamos convencidos de que ao sofrerem a experiência do deslocamento clássicos como Humboldt, Ratzel, Mackinder e Vidal de la Blache (para citar apenas alguns) passam a ser expostos a questões particulares à conjuntura que os traduziu e, destarte, podem ser examinados de maneiras diferentes em relação aos seus contextos de origem (vide Rupke, 2000; Keighren, 2010). Tradução não é cópia e nem repetição "sofisticada" a ser apropriada por uma embalsamada história das ideias, mas uma sorte de utopia políticoepistemológica destinada a viabilizar a interrogação permanente do processo histórico e de suas narrativas hegemônicas. Logo, não se trata de mera reprodução, mas, antes, da produção do novo (Italiano, 2016; Benjamin, 2013 [1921]).

Trazer mais uma vez Vidal de la Blache ao Brasil tem por intuito convidar o leitor brasileiro a pensar sobre como ele entendia a posse dos territórios coloniais, mas também o de provocar reflexão sobre a influência francesa exercida sobre nossa intelectualidade, por exemplo. Afinal, naturalizar a língua significa naturalizar o próprio pensamento e, subjacente a isto, ignorar seu lugar de fala - sobretudo em um país periférico, cuja condição praticamente nos obriga a meditar a partir de referenciais alheios a fim, inclusive, de obter legitimação (ver Spivak, 2010 [1985]). Consciente ou inconscientemente, nós mesmos somos os responsáveis pela alimentação de uma estrutura científica hierárquica e assimétrica na qual as periferias vêm assumindo papel de repositório de ideias formuladas pelos centros.

5 Eis o porquê de nos situarmos junto às abordagens críticas sobre tradução (e, obviamente, sobre o papel das línguas [Germes \& Husseini de Araújo, 2016; Minca, 2000; Aalbers, 2004]), pois expressões supostamente consensuais associadas a ela como "difusão do saber" e "intercâmbio de ideias" - ou, como no caso da seção do Boletim 
Geográfico denominada "transcrições" - encobrem o fato de que traduções têm sido amiúde mobilizadas pelo status quo acadêmico justamente na reprodução daquela estrutura. Cabe, portanto, retirar as traduções do silêncio a que têm sido submetidas e transformá-las ao mesmo tempo em método de investigação de uma história prospectiva da geografia e em ferramentas de ressonância de vozes provenientes do Sul Global (Mezzadra \& Nielson, 2013). Afinal, não resta a menor dúvida de que traduzir é uma poderosa forma de "desobediência epistêmica" (Mignolo, 2009).

7 No contexto de disputa por espaço no campo científico das primeiras décadas do século XX na França, a interpretação partidária e lacunar do historiador Lucien Febvre cravou sem pudor algum a noção de uma geografia humana modesta, ciência dos lugares proibida de analisar a política, o Estado e a economia e cujo papel se limitaria a servir de palco introdutório aos processos históricos. $O$ resultado não foi outro senão o empobrecimento das obras de dois dos maiores geógrafos da modernidade: o francês Vidal de la Blache e o alemão Ratzel (Febvre, 1991 [1922]; Ribeiro, 2009).

Escrito oito anos antes da publicação de La terre et l'évolution humaine: introduction géographique à l'histoire, Vidal parece querer esclarecer em Sur l'esprit géographique [Sobre o raciocínio geográfico] a definição de ciência dos lugares e não dos homens enunciada no ano anterior em um de seus textos mais populares: Des caractères distinctifs de la géographie (Vidal de la Blache, 1913). Tudo indica que tal definição não foi mesmo feliz, mas ela está longe de justificar leituras como as de Febvre. Muito pelo contrário, com base nas heranças de Humboldt e Ritter e nos progressos de seu contemporâneo Ratzel Vidal esmera-se em conceber a particularidade epistemológica de uma nova geografia em meio a disciplinas ora parceiras, ora rivais como História, Sociologia, Biologia e Geologia e à luz de uma conjuntura marcada, de um lado, pelo choque econômicoprodutivo a subverter os tradicionais nexos campo-cidade e, de outro, pela alteração na relação entre os lugares possibilitada pelas técnicas de transportes e de comunicações.

Plenamente ciente da condição histórica da ciência geográfica, Vidal pretende realizar uma espécie de atualização do passado ao incorporar o papel do ambiente à vida social, porém necessariamente atrelado ao papel da agência humana em sua modificação. Se outrora lidar com os humores do clima, o controle dos cursos d'água, as formas do relevo e os tipos de solo representava algo muito mais complexo e laborioso em todos os sentidos, o século XIX consagra o poder do homem moderno ao metamorfosear a superfície terrestre a ponto de expandir o ecúmeno a uma escala nunca antes alcançada. Escala, aqui, é palavra-chave, pois a concorrência imperial catalisada pela revolução industrial retraiu o mundo inteiro ao integrar os mercados metropolitanos às áreas agrícolas coloniais e a consequência espacial disto foi justamente a aproximação entre os lugares. Assim, se todas as escalas foram afetadas, para a geografia um dos fundamentos metodológicos mais importantes é a comparação, permitindo o entendimento tanto dos mecanismos gerais quanto das circunstâncias locais a moldarem a diversidade paisagística de regiões, territórios e continentes (Vidal de la Blache, 1914: 358). Nesse quadro, ao referir-se às influências do solo, Vidal não se limita à sua composição orgânica, mas a uma gama de aspectos como posição, situação, maritimidade, continentalidade e extensão. Da mesma maneira, ao explorar a relevância da localização ele não pensa apenas nas coordenadas rígidas de latitude e longitude, mas nas redes de conexões a partir das quais lugares tecem e desfazem influências, hegemonias, intercâmbios; em síntese, estabelecem seu diálogo com o 
mundo. Localizar passa a ser um gênero complexo de raciocínio que demanda não apenas a capacidade de reconhecer elementos da natureza ou eventos históricos, mas que exige abordá-los sob a forma de um amálgama sui generis de interações. Embora continuasse a preservar seu antigo nome grego geographia, estamos diante de um aggiornamento tipicamente moderno no qual fórmulas simplistas a explicar a história pela geografia ou a geografia pela história não só estariam em descompasso com o dinamismo científico de então como seriam incapazes de contemplar a realidade. Para Vidal, o objeto da geografia deveria ser concebido segundo um esquema de método no qual tempo e lugar não eram categorias a priori, mas conceitos submetidos ao processo histórico e, em virtude disto, as noções quando e onde restariam indissociáveis. Em síntese, "A necessidade de localizar confunde-se com a necessidade de compreender" (idem).

Gostaríamos de sondar um pouco mais a fortuna temporal vidaliana avançando em seus prováveis efeitos sobre a longa duração desenvolvida pelos Annales de Marc Bloch, Lucien Febvre e Fernand Braudel, além de indicar outros artigos que nos resguardariam de narrativas segundo as quais a geografia "clássica" não definiu a contento seu objeto e seu método - já que esta última questão permeou (desviou?) o debate epistemológico na geografia durante o século passado (vide Ribeiro, 2017, 2012).

11 Entretanto, no pouco espaço de que dispomos, contentemo-nos em grifar a atualidade de seu legado pois, como intérprete da modernidade, os desafios de seu tempo admitem certa semelhança com os nossos dias. Toute proportion gardée, nota-se certa inspiração vidaliana na obra-prima de Milton Santos A natureza do espaço (Santos, 1996). Publicada no ano de 1996, seu tom fin-de-siècle, a busca por uma síntese geográfica renovada capaz de explicar o período histórico da globalização e a presença nuclear das técnicas na organização do meio nos remetem aos Principes de géographie humaine, livro póstumo compilado por seu genro Emmanuel de Martonne em 1921 cujo objetivo também era o de apreender as principais feições espaço-temporais na época do colonialismo na virada do século XIX para o XX. Para tanto, Vidal observara ferrovias de longo alcance e linhas marítimas intercontinentais intensificando fluxos e redes migratórios e de mercadorias, o impacto da indústria sobre as estruturas agrárias e os antigos pays implicando na valorização das cidades e a consagração do mundo como unidade analítica e empírica para os fenômenos geográficos. Em suma, a emergência de uma nova configuração escalar (Vidal de la Blache, 1954 [1921]).

12 Mais que digressão ou exclusividade de historiadores da geografia, ler Vidal de la Blache hoje é uma experiência tão inusitada que nos transporta de volta para o futuro. Sobre o raciocínio geográfico é apenas uma pequena amostra.

\section{BIBLIOGRAFIA}

Aalbers, Manuel B. (2004). "Creative destruction through the Anglo-American hegemony: a nonAnglo-American view on publications, referees and language". Area, v. 36, n. 3, pp. 319-322. 
Benjamin, Walter (2013 [1921]). “A tarefa do tradutor”. In: Benjamin, Walter. Escritos sobre mito e linguagem. São Paulo: Duas Cidades/Editora 34.

Febvre, Lucien (1991 [1922]). A terra e a evolução humana. Introdução geográfica à história. 2. ed. Lisboa: Cosmos.

Germes, Mélina, Husseini de Araújo, Shadia (2016). "For a critical practice of translation in geography”. ACME: an international journal for critical geographies, v. 15, n. 1, pp. 1-14.

Italiano, Federico (2016). Translation and Geography. London and New York: Routledge.

Keighren, Innes M. (2010). Bringing geography to book: Ellen Semple and the reception of geographical knowledge. London: I.B.Tauris.

Mignolo, Walter (2009). "Epistemic disobedience, independent thought and de-colonial freedom". Theory, Culture \& Society, v. 26, n. 7-8, pp. 1-23.

Minca, Claudio (2000). “Venetian geographical praxis”. Society and Space, v. 18, pp. 285-289.

Mezzadra, Sandro; Neilson, Brett (2013). Border as method, or, the multiplication of labor. Durham and London: Duke University Press.

Ribeiro, Guilherme (2017). Fernand Braudel, geohistória e longa duração. Críticas e virtudes de um projeto historiográfico. São Paulo: Annabume.

Ribeiro, Guilherme (2012). "Fundamentos epistemológicos de uma ciência”. In: Haesbaert, Rogério; Pereira, Sergio Nunes; Ribeiro, Guilherme (Orgs.). Vidal, Vidais. Textos de geografia humana, regional e política. Rio de Janeiro: Bertrand Brasil, pp. 23-40.

Ribeiro, Guilherme (2009). "Para ler Geografia ou A Geografia segundo Lucien Febvre”. Terra Livre, n. 32 , v. 1, pp. 121-136.

Rupke, Nicolaas (2000). "Translation studies in the history of science: the example of Vestiges". British Journal for the History of Science, v. 33, n. 2, pp. 209-222.

Santos, Milton (1996). A natureza do espaço. Técnica e tempo. Razão e emoção. São Paulo: Hucitec.

Spivak, Gayatri Chakravorty (2010 [1985]). Pode o subalterno falar? Belo Horizonte: Editora UFMG.

Vidal de la Blache, Paul (1954 [1921]). Princípios de geografia humana. Lisboa: Cosmos.

Vidal de la Blache, Paul (1914). "Sur l'esprit géographique". Revue politique et littéraire (Revue Bleu), n.13, 1er sem., 52e année, 2 mai, pp. 556-560.

Vidal de la Blache, Paul (1913). "Des caractères distinctifs de la géographie". Annales de Géographie, année XXII, n.124, pp. 289-299.

\section{RESUMOS}

Em um contexto de disputa entre as ciências no início do século vinte na França e visando conferir especificidade à geografia porém sem abrir mão da interdisciplinaridade, Paul Vidal de la Blache concebe em Sobre o raciocínio geográfico (1914) um objeto e um método assentado respectivamente nas correlações entre o homem e o meio ambiente sob uma perspectiva histórica e na articulação entre os lugares intensificada pelo Colonialismo e pela Revolução Industrial. Embora nem sempre lembradas pela atual geração, cem anos depois suas ideias continuam úteis para pensarmos a experiência geográfica de um mundo cada vez mais global. Traduzi-lo para o Brasil permite tanto repensar seu legado quanto mobilizar a história da geografia em direção ao futuro. 
In a context of scientific disputes at the beginning of the 20th century in France, Paul Vidal de la Blache tries to find the geographical specialness without forgoing interdisciplinarity. To do this, Sur l'esprit géographique (1914) drafts an object and a method reasoned in the correlations between man and the environment under a historical perspective and on the connections among places intensified by colonialism and industrial revolution. Even though his ideas are not always remembered by current generations, one hundred years later they remain important to consider about the geographical experience of an increasingly global world. Translate Vidal de la Blache to Brazil in the 21th century allows both to rethink his legacy and to mobilize the history of geography toward the future.

Dans un contexte de rivalité scientifique au début du XXème siècle en France, Vidal de la Blache veut imprimer la particularité de la géographie mais sans oublier l'interdisciplinarité. Pour ce faire, dans l'article Sur l'esprit géographique (1914) il développe un objet et une méthode appuyée sur les rapports homme-milieu sous une perspective historique et sur les liaisons entre les lieux intensifiés par la Révolution Industrielle et le Colonialisme. Même si ses idées ne sont pas toujours rappelées par l'actuel génération, elles restent utiles si l'on veut réfléchir sur les expériences géographiques dans un monde chaque fois plus global. Le traduire au Brésil au XXIème siècle nous permet de repenser son héritage mais aussi de mobiliser l'histoire de la géographie vers l'avenir.

En un contexto de disputa entre las ciencias a principios del siglo XX en Francia y con el objetivo de dar especificidad a la geografía, pero sin renunciar a la interdisciplinariedad, Paul Vidal de la Blache concibe en Sur l'esprit géographique (1914) un objeto y un método basados respectivamente en las correlaciones entre el hombre y el medio ambiente desde una perspectiva histórica y en la articulación entre lugares intensificados por el colonialismo y la revolución industrial. Aunque no siempre es recordado por las nuevas generaciones, cien años después sus ideas siguen siendo útiles para pensar en la experiencia geográfica de un mundo cada vez más global. Traducir Vidal de la Blache en el Brasil del siglo XXI permite repensar su legado y movilizar la historia de la geografía hacia el futuro.

\section{ÍNDICE}

\section{Índice geográfico: França}

Índice cronológico: 1914

Mots-clés: épistémologie, le concept de lieu, géographie humaine, histoire de la géographie, Vidal de la Blache

Palavras-chave: epistemologia, conceito de lugar, geografia humana, história da geografia, Vidal de la Blache

Palabras claves: epistemología, el concepto de lugar, geografía humana, historia de la geografía, Vidal de la Blache

Keywords: epistemology, concept of place, human geography, history of geography, Vidal de la Blache

\section{AUTOR}

\section{GUILHERME RIBEIRO}

Laboratório Política, Epistemologia e História da Geografia, Departamento de Geografia, Programa de Pós-Graduação em Geografia, Universidade Federal Rural do Rio de Janeiro 
(LAPEHGE/PPGGEO/UFRRJ).

E-mail: geofilos@msn.com 